\title{
Interação entre salinidade e bioestimulante na cultura do feijão caupi
}

\author{
Francisco de A. de Oliveira', José F. de Medeiros', Mychelle K. T. de Oliveira', \\ Antônia A. T. Souza' ${ }^{1}$, José A. Ferreira' ${ }^{1}$ \& Mateus S. Souza' ${ }^{1}$
}

\begin{abstract}
RESUMO
Objetivou-se, neste trabalho, avaliar a interação entre salinidade e o uso de bioestimulante (Stimulate ${ }^{\circledR}$ ) sobre o desenvolvimento do feijão caupi. A semeadura foi feita em vasos utilizando-se, como substrato, um Argissolo Vermelho Amarelo. O experimento obedeceu a um delineamento inteiramente casualizado em esquema fatorial $2 \times 7$. Os tratamentos se constituíram da combinação de dois níveis de sais da água de irrigação e seis formas de aplicação de bioestimulante (Ausência, Tratamento de sementes, Foliar aos 20 dias após semeadura (DAS), Foliar aos 40 DAS, Tratamentos de sementes + Foliar aos 20 DAS, Tratamento de sementes + foliar aos 40 DAS e Aplicação foliar aos 20 e 40 DAS). Foram realizadas duas avaliações não destrutivas (20 e 40 DAS) e uma destrutiva (60 DAS) e avaliados a altura, o número de folhas, a área foliar e a massa seca de folhas, de caule e da parte aérea. Todos os parâmetros fisiológicos avaliados foram afetados pela salinidade. Nas formas de aplicação adotadas o bioestimulante não proporcionou melhorias no desenvolvimento das plantas quando submetidas ao estresse salino; a salinidade inibiu o efeito benéfico do bioestimulante sobre o desenvolvimento do feijão caupi; enfim, o uso de bioestimulante não é viável em plantas cultivadas sob estresse salino.
\end{abstract}

Palavras-chave: Vigna unguiculata, estresse salino, fitorreguladores

\section{Interaction between water salinity and biostimulant in the cowpea plants}

\begin{abstract}
The objective of this study was to evaluate the interaction between salinity levels of the water and the use of biostimulant (Stimulate ${ }^{\circ}$ ) in the initial development stage of cowpea plants. The sowing of seeds was done in pots, using as a substrate Alfissol and two plants per pot. The experimental design was completely randomized in a $2 \times 7$ factorial scheme. The treatments consisted of combination of two salinity levels $(0.5$ and $5.0 \mathrm{dS} \mathrm{m}^{-1}$ ) with seven biostimulant application forms (without application, seed treatment, sprinkled 20 days after sowing (DAS), sprinkled 40 DAS, seed treatment + sprinkled 20 DAS, seed treatment + sprinkled 40 DAS and sprinkled 20 and 40 DAS). Two non destructive evaluations (20 and 40 DAS) and one destructive evaluation (60 DAS) were performed. Plant height, number of leaves, leaf area, and dry mater of leaves, stem and aerial parts were evaluated. All parameters were influenced by salinity. The biostimulant in the adopted forms of application did not render any improvement on plant development when submitted to saline stress. The salinity inhibited the beneficial effects of the biostimulant on the growth of the cowpea plants therefore, the use of plant growth regulator is not feasible in plants grown under salt stress.
\end{abstract}

Key words: Vigna unguiculata, saline stress, plant regulators 


\section{INTRODUÇÃO}

O feijão caupi é uma das culturas mais importantes para a população brasileira, especialmente na região Nordeste. Apesar de esta cultura ser considerada por muitos como de subsistência, a viabilidade do uso da irrigação tem sido estudada por diversos pesquisadores, sendo encontrados resultados demonstrando que a prática da irrigação garante a viabilidade econômica do cultivo de feijão caupi (Mousinho et al., 2008).

Além da disponibilidade, a qualidade da água é fator de fundamental importância para obtenção de elevadas produtividades. Dentre as características que determinam a qualidade da água para a irrigação a concentração de sais solúveis ou salinidade, é um dos principais fatores limitantes ao crescimento e desenvolvimento de algumas culturas (Bezerra et al., 2010).

A inibição do crescimento das plantas sob salinidade ocorre por duas razões: a primeira se deve ao efeito osmótico provocado pela salinidade, que reduz a absorção de água e a segunda se dá devido ao efeito específico dos íons ou ao excesso, que entram no fluxo de transpiração e, eventualmente, causam injúrias nas folhas reduzindo o crescimento ou influenciando negativamente na absorção de elementos essenciais (Munns, 2005).

O feijão caupi é considerado uma espécie moderadamente tolerante à salinidade da água de irrigação apresentando salinidade limiar de 3,3 $\mathrm{dS} \mathrm{m}^{-1}$ (Ayers \& Westcot, 1999). No entanto, pesquisas têm demonstrado que a elevação da salinidade do solo decorrente da irrigação com água salina inibiu o desenvolvimento das plantas em consequência da redução na fotossíntese, transpiração e condutância estomática (Neves et al., 2009; Silva et al., 2011) afetando ainda os processos de absorção, transporte, assimilação e distribuição de nutrientes reduzindo, em consequência, o desenvolvimento e o rendimento da cultura (Neves et al., 2009; Bezerra et al., 2010).

Diante desta problemática uma série de pesquisas tem sido desenvolvida objetivando estratégias de manejo da cultura que possibilite o uso de água salina na irrigação das plantas sem que afete negativamente a produção nem a qualidade dos produtos, como rotação de cultura (Bezerra et al., 2010; Lacerda et al., 2011), uso de águas salinas em diferentes fases da cultura (Neves et al., 2009), aplicação de silício (Lima et al., 2011) ou de biofertilizantes (Silva et al., 2011).

Atualmente, o emprego de fitorreguladores como técnica agronômica para se otimizar as produções em diversas culturas, tem crescido nos últimos anos. Bioestimulantes vegetais são combinações de biorreguladores ou de biorreguladores e outras substâncias que, aplicadas exogenamente, possuem ações similares aos grupos de hormônios vegetais conhecidos (Castro \& Vieira, 2001).

No entanto, alguns pesquisadores têm observado que o efeito do bioestimulante pode ser influenciado por fatores genéticos (Bertolin et al., 2010) e ambientais (Ávila et al., 2010). Baldo et al. (2009) verificaram, trabalhando com a cultura do algodoeiro, que o uso do biostimulante não proporcionou melhoria ao desenvolvimento das plantas quando submetidas à deficiência hídrica.

Esses resultados demonstram que para se obter a maior eficiência do biostimulante na produção agrícola é fundamental o desenvolvimento de pesquisas sob diferentes condições ambientais de cultivo.

Levando-se em consideração que o Stimulate ${ }^{\circledR}$ tem, em sua constituição, o ácido indolbutírico (auxina) $0,005 \%$, cinetina (citocinina) 0,009\% e o ácido giberélico (giberelina) 0,005\%, sendo eles biorreguladores de crescimento vegetal que atuam como mediadores de processos fisiológicos, acredita-se que este biorregulador pode, em função de sua composição, concentração e proporção das substâncias, incrementar o crescimento e o desenvolvimento vegetal estimulando a divisão celular podendo também aumentar a absorção de água e nutrientes pelas plantas (Vieira \& Castro, 2004).

Devido às características acima descritas, o bioestimulante pode ser uma alternativa como agente amenizador do efeito deletério da salinidade sobre o feijão caupi, no entanto, são escassos estudos sobre o uso deste produto em plantas submetidas ao estresse salino. Assim, este trabalho foi desenvolvido com o objetivo de avaliar a efeito do uso de água salina e da aplicação de bioestimulante na cultura do feijão caupi.

\section{Material e Métodos}

O experimento foi desenvolvido em casa de vegetação no Departamento de Ciências Vegetais da Universidade Federal Rural do Semiárido (UFERSA), localizada nas coordenadas geográficas de $5^{\circ} 11^{\prime} 31^{\prime \prime}$ de latitude Sul e $37^{\circ} 20^{\prime} 40^{\prime \prime}$ de longitude Oeste de Greenwich, com altitude média de $18 \mathrm{~m}$. Foi utilizado material de solo classificado como Argissolo Vermelho Amarelo (EMBRAPA, 2006), coletado na camada de 0-20 cm de profundidade em área não cultivada localizada no Campus da UFERSA. O material coletado foi secado ao ar e posteriormente peneirado em malha de 2,0 $\mathrm{mm}$; antes do acomodamento do solo nos vasos foi retirada uma subamostra para ser submetida a análise físico-químicas (EMBRAPA, 1997) cujos resultados são apresentados na Tabela 1.

Tabela 1. Características físicas e químicas do solo utilizado no experimento

\begin{tabular}{|c|c|c|c|c|c|c|c|c|}
\hline \multicolumn{9}{|c|}{ Características químicas } \\
\hline $\mathrm{pH}$ & M.0. & $\mathbf{P}$ & $\mathbf{K}^{+}$ & $\mathrm{Na}^{+}$ & $\mathrm{Ca}^{+2}$ & $\mathrm{Mg}^{+2}$ & $\mathrm{Al}^{+3}$ & $\mathbf{H}^{+}$ \\
\hline 5,3 & 1,05 & 2,20 & 0,14 & 0,13 & 0,40 & 0,60 & 0,25 & 3,05 \\
\hline \multicolumn{3}{|c|}{ Fração granulométrica $\left(\mathrm{g} \mathrm{kg}^{-1}\right)$} & Classe & \multicolumn{2}{|c|}{ Umidade $\left(\mathrm{g} \mathrm{g}^{-1}\right)$} & \multicolumn{3}{|c|}{ Densidade $\left(\mathrm{kg} \mathrm{dm}^{-3}\right)$} \\
\hline Areia & Silte & Argila & textural & CC & PMP & Ds & & Dp \\
\hline 707,2 & 172,2 & 120,6 & FA & 0,15 & 0,06 & 1,53 & & 2,68 \\
\hline
\end{tabular}


Utilizou-se o delineamento inteiramente casualizado, seguindo arranjo fatorial $2 \times 7$, com três repetições resultando no total de 42 unidades experimentais, cada uma representada por um vaso com capacidade para $10 \mathrm{~L}$, contendo duas plantas.

Os tratamentos foram resultantes da combinação de dois níveis de salinidade da água de irrigação $\left(0,5\right.$ e 5,0 dS m $\left.{ }^{-1}\right)$ com sete formas de aplicação de bioestimulante (ausência, tratamentos de sementes, foliar aos 20 DAS, foliar aos 40 DAS, tratamentos de sementes + foliar aos 20 DAS, tratamento de sementes + foliar aos 40 DAS e aplicação foliar aos 20 e 40 DAS). Essas formas de aplicação foram utilizadas em virtude de alguns autores terem encontrado diferentes respostas das plantas em função de formas e épocas de aplicação de Stimulate ${ }^{\circledR}$ (Klahold et al., 2006; Bertolin et al., 2010; Abrantes et al., 2011).

Para a salinidade $\mathrm{S}_{1}-0,5 \mathrm{dS} \mathrm{m}^{-1}$ foi utilizada água proveniente do sistema de abastecimento do campus da UFERSA cujas análises físicas e químicas determinaram as seguintes características: $\mathrm{pH}=8,30 ; \mathrm{CE}=0,50 \mathrm{dS} \mathrm{m}^{-1} ; \mathrm{Ca}^{2+}=3,10 ; \mathrm{Mg}^{2+}=1,10$; $\mathrm{K}^{+}=0,30 ; \mathrm{Na}^{+}=2,30 ; \mathrm{Cl}^{-}=1,80 ; \mathrm{HCO}_{3}^{-}=3,00 ; \mathrm{CO}_{3}{ }^{2-}=0,20$ $\left(\mathrm{mmol}_{\mathrm{c}} \mathrm{L}^{-1}\right)$. Para obtenção da água de alta salinidade $\left(\mathrm{S}_{2}=5,0\right.$ $\mathrm{dS} \mathrm{m}^{-1}$ ) foi adicionada, à água de salinidade $\left(\mathrm{S}_{1}\right)$, uma mistura de sais $\left(\mathrm{NaCl}, \mathrm{CaCl}_{2} \cdot 2 \mathrm{H}_{2} \mathrm{O}\right.$ e $\left.\mathrm{MgCl}_{2} \cdot 6 \mathrm{H}_{2} \mathrm{O}\right)$ mantendo-se a proporção equivalente de 7:2:1 (Medeiros, 1992).

Realizou-se a semeadura colocando-se cinco sementes de feijão caupi cv. "Quarentinha", realizando-se o desbaste cinco dias após a semeadura deixando-se as duas plantas mais vigorosas em cada vaso.

Nos tratamentos com aplicação do bioestimulante via tratamento de sementes foi utilizada a dosagem de $5 \mathrm{~mL}$ Stimulate ${ }^{\circledR}$ por $0,5 \mathrm{~kg}$ de sementes de caupi. O produto foi aplicado diretamente sobre as sementes, com auxílio de uma pipeta graduada; para tanto, as sementes foram acondicionadas em sacos plásticos transparentes, que foram inflados e agitados vigorosamente durante um minuto visando uniformizar a distribuição do produto sobre a massa de sementes; em seguida, as sementes foram colocadas para secar à sombra sobre papel toalha, durante uma hora.

Para os tratamentos que não receberam o bioestimulante via tratamento de sementes (ausência, Foliar aos 20 DAS, Foliar aos 40 DAS e Foliar aos 20 e 40 DAS), as sementes passaram pelo mesmo procedimento das demais utilizando-se água destilada no lugar do bioestimulante.

As aplicações do bioestimulante via foliar foram realizadas através de um pulverizador costal com capacidade para 5,0 L, sendo a calda preparada na dose de $2,0 \mathrm{~L} \mathrm{ha}^{-1}$ e se considerando um volume de calda equivalente a $300 \mathrm{~L} \mathrm{ha}^{-1}$ (Abrantes et al., 2011). Para garantir uma distribuição uniforme para todos os vasos durante a pulverização, os vasos eram postos em fileira e em seguida aplicados o bioestimulante tomando-se, porém todo cuidado para alcançar uma faixa de 1,5 m de largura e 1,0 $\mathrm{m}$ distante de cada vaso no início da fileira.

Foram realizadas duas avaliações de crescimento ao longo do experimento sendo a primeira de forma não destrutiva, em intervalos de 20 dias, que coincidiram com as etapas de aplicação foliar do bioestimulante, avaliando-se as seguintes variáveis: altura, número de folhas e área foliar. A área foliar foi estimada utilizando-se medidas lineares de comprimento e largura do limbo foliar (Lima et al., 2008).
Aos 60 dias após a semeadura (DAS) as plantas foram coletadas e analisadas (análise destrutiva) quanto ao número de folhas, área foliar, altura de plantas, massa seca de folhas, de caule e da parte aérea. Os dados obtidos foram submetidos à análise de variância e as médias comparadas entre si pelo teste de Tukey a nível de significância de 0,05 de probabilidade. As análises estatísticas foram realizadas utilizando-se software estatístico SISVAR versão 4.2

\section{Resultados e Discussão}

A análise de variância mostrou que houve interação entre os fatores salinidade da água de irrigação e bioestimulante sobre número de folhas (NF) aos $40 \mathrm{DAS}$, área foliar (AF) aos 60 DAS e para massa seca de caule (MSC) a nível de significância de 0,05 enquanto para massa seca de folhas (MSF) e da parte aérea (MSPA) ocorreu interação significativa a nível de 0,01 de probabilidade pelo teste ' $F$ '. As diferentes salinidades da água de irrigação influenciaram isoladamente as ALT, NF e $\mathrm{AF}$ aos 40 e 60 DAS, além das MSC, MSF e MSPA; já para o bioestimulante verificou-se resposta significativa a nível de 0,05 para NF (40 DAS) e MSC a nível de 0,05 e significância de 0,01 para NF (60 DAS), AF (20, 40 e 60 DAS) e MSF (Tabela 2).

Tabela 2. Valores dos quadrados médios e da significância estatística para altura de plantas, número de folhas, área foliar, massa seca de folhas (MSF), de caule (MSC) e da parte aérea (MSPA) do feijoeiro caupi, em função do estresse salino e aplicação de bioestimulante

\begin{tabular}{|c|c|c|c|c|}
\hline & \multicolumn{3}{|c|}{ Fontes de variação } & \multirow{2}{*}{ CV } \\
\hline & Salinidade & Bioestimulante & Interação & \\
\hline \multicolumn{5}{|c|}{ Altura de plantas } \\
\hline $20 \mathrm{DAS}$ & $0,26^{\mathrm{ns}}$ & $1,88^{\mathrm{ns}}$ & $1,17^{\text {ns }}$ & 12,49 \\
\hline $40 \mathrm{DAS}$ & $46,07 * *$ & $5,27^{\mathrm{ns}}$ & $0,41^{\mathrm{ns}}$ & 9,90 \\
\hline $60 \mathrm{DAS}$ & $146,72^{\star \star}$ & $10,76^{\mathrm{ns}}$ & $3,47^{\text {ns }}$ & 11,45 \\
\hline \multicolumn{5}{|c|}{ Número de folhas } \\
\hline $20 \mathrm{DAS}$ & $2,52^{\mathrm{ns}}$ & $4,67^{\mathrm{ns}}$ & $2,52^{\mathrm{ns}}$ & 14,77 \\
\hline 40 DAS & $2016,67^{\star \star}$ & 45,24 * & $413,03^{\star}$ & 8,74 \\
\hline $60 \mathrm{DAS}$ & $5940,48^{* \star}$ & 100,26 ** & $34,49^{\text {ns }}$ & 13,34 \\
\hline \multicolumn{5}{|c|}{ Área foliar } \\
\hline $20 \mathrm{DAS}$ & $992,3^{\text {ns }}$ & $8413,3^{* *}$ & $9,6^{\mathrm{ns}}$ & 15,5 \\
\hline $40 \mathrm{DAS}$ & $4038640,5^{\star *}$ & $390484,9 * *$ & $46407,4^{\text {ns }}$ & 13,3 \\
\hline $60 \mathrm{DAS}$ & 10072463,0 ** & 34441749,0 ** & $16560082,0^{*}$ & 16,6 \\
\hline \multicolumn{5}{|c|}{ Massa seca } \\
\hline MSF & $1665,3^{\star \star}$ & $38,9^{\star \star}$ & $93,9 * \star$ & 16,5 \\
\hline MSC & $3988,5^{* *}$ & $19,3^{*}$ & $22,8^{*}$ & 12,1 \\
\hline MSPA & $10808,1^{* *}$ & $47,2^{\text {ns }}$ & $177,7^{* *}$ & 13,5 \\
\hline
\end{tabular}

A altura das plantas aos 20 dias após a semeadura (DAS) não foi afetada pela interação entre os fatores nem pelos fatores isoladamente, obtendo-se altura média de 10,3 cm (Tabela 3). A ausência da resposta na altura das plantas em função da salinidade pode ser explicada pelo curto espaço de tempo para avaliação (20 DAS), de forma que houve pequeno acúmulo de sais no solo.

A salinidade da água utilizada na irrigação afetou isoladamente e significativamente a altura das plantas aos 40 e 60 DAS, independente do uso de bioestimulante, e as maiores plantas foram obtidas com água de salinidade 0,5 $\mathrm{dS} \mathrm{m}{ }^{-1}$, com altura média de 20,3 e $21,4 \mathrm{~cm}$ aos 40 e 60 DAS, respectivamente. Na maior salinidade $\left(5,0 \mathrm{dS} \mathrm{m}^{-1}\right)$ 
Tabela 3. Valores médios para altura (cm) de plantas de feijão caupi aos 20, 40 e 60 dias após a semeadura (DAS), em função da salinidade da água e aplicação de bioestimulante

\begin{tabular}{|c|c|c|c|c|c|c|c|c|c|}
\hline \multirow{3}{*}{ Bioestimulante } & \multicolumn{9}{|c|}{ Salinidades $\left(\mathrm{dS} \mathrm{m}^{-1}\right)$} \\
\hline & 0,5 & 5,0 & \multirow{2}{*}{ Média } & 0,5 & 5,0 & \multirow{2}{*}{ Média } & 0,5 & 5,0 & \multirow{2}{*}{ Média } \\
\hline & \multicolumn{2}{|c|}{20 DAS } & & \multicolumn{2}{|c|}{40 DAS } & & \multicolumn{2}{|c|}{60 DAS } & \\
\hline Ausência & 10,6 & 10,9 & $10,7 \mathrm{a}$ & 18,9 & 16,7 & $17,8 \mathrm{a}$ & 18,9 & 16,7 & $17,8 \mathrm{a}$ \\
\hline Sementes & 10,4 & 9,7 & $9,9 \mathrm{a}$ & 21,5 & 18,2 & $19,8 \mathrm{a}$ & 21,5 & 18,2 & $19,9 \mathrm{a}$ \\
\hline Foliar (20 DAS) & - & - & - & 19,8 & 17,3 & $18,5 \mathrm{a}$ & 21,2 & 18,0 & $19,5 \mathrm{a}$ \\
\hline Foliar (40 DAS) & - & - & - & 21,2 & 18,0 & $19,5 \mathrm{a}$ & 22,9 & 18,3 & $20,6 \mathrm{a}$ \\
\hline Sementes + foliar (20 DAS) & - & - & - & - & - & - & 19,8 & 17,3 & $18,6 \mathrm{a}$ \\
\hline Sementes + foliar (40 DAS) & - & - & - & - & - & - & 20,5 & 16,7 & $18,7 \mathrm{a}$ \\
\hline Foliares (20 e 40 DAS) & - & - & - & - & - & - & 25,1 & 18,4 & $21,7 \mathrm{a}$ \\
\hline Médias & $10,5 A^{*}$ & $10,2 \mathrm{~A}$ & & $20,3 \mathrm{~A}$ & $17,6 \mathrm{~B}$ & & $21,4 \mathrm{~A}$ & $17,6 \mathrm{~B}$ & \\
\hline
\end{tabular}

* Médias seguidas pelas mesmas letras maiúsculas nas linhas e minúsculas nas colunas não diferem entre si pelo teste de Tukey a 0,05 de probabilidade

foram observados os menores valores, com 17,6 e $17,7 \mathrm{~cm}$, respectivamente, correspondendo a reduções de $13,3 \%$ aos 40 DAS e $17,4 \%$ aos 60 DAS (Tabela 3 ).

Não se observou efeito significativo do bioestimulante sobre a altura das plantas em nenhuma das avaliações obtendose altura média de $10,3,18,9$ e $19,5 \mathrm{~cm}$, aos 20,40 e 60 DAS, respectivamente (Tabela 3). Esses resultados estão de acordo com os obtidos por Abrantes et al. (2011) que, embora trabalhando com duas cultivares de feijoeiro (Phaseolus vulgaris) e utilizando diferentes formas e épocas de aplicação de Stimulate ${ }^{\circledR}$, não encontraram diferenças na altura das plantas em resposta ao bioestimulante. Trabalhos desenvolvidos com outras culturas também não apresentaram efeito do bioestimulante sobre a altura das plantas, a exemplo de Klahold et al. (2006) trabalhando com a cultura da soja e Garcia et al. (2009) com a cultura do arroz.

Não houve resposta do feijoeiro aos tratamentos aplicados sobre o número de folhas aos $20 \mathrm{DAS}$, obtendo-se valor médio de 9,4 folhas planta $^{-1}$. Na avaliação realizada aos 40 DAS verificou-se interação significativa entre os fatores salinidade e bioestimulantes, de forma que foi realizado o desdobramento para avaliar o efeito da salinidade em cada forma de aplicação, além de efeito do bioestimulante em cada nível de salinidade. Avaliando o efeito da salinidade verificou-se diminuição do número de folha com o aumento da salinidade, com perdas variando de 25,3 a $46,5 \%$ na ausência de bioestimulante e na aplicação via tratamento nas sementes, respectivamente, demonstrando que a aplicação do bioestimulante via tratamento de sementes aumentou o efeito deletério da salinidade sobre a emissão foliar das plantas (Tabela 4).

Realizando o desdobramento para avaliar o efeito do bioestimulante em cada nível de salinidade, verificou-se que na salinidade de $0,5 \mathrm{dS} \mathrm{m}^{-1}$ o maior número de folhas ocorreu nas aplicações via semente e foliar 20 DAS, que não diferiram do tratamento ausência do produto, obtendo valor médio de 47,7 folhas. Constatou-se diferença percentual de aproximadamente $11,7 \%$ entre o valor obtido com duas aplicações (sementes + foliar 20 DAS) e os demais tratamentos (Tabela 4). Domingues et al. (2004) verificaram, testando o efeito do Stimulate ${ }^{\circledR}$ na cultura da soja, aumento no número de folhas, em aplicação foliar e no tratamento de sementes.

Para as plantas irrigadas com água de maior salinidade observou-se que a aplicação de bioestimulante resultou em maior sensibilidade das plantas à salinidade, principalmente nos tratamentos que receberam o bioestimulante via sementes, tendo-se observado os menores valores, com média de 24,9 folhas por planta; os maiores valores foram obtidos na ausência do bioestimulante (33,2 folhas planta $\left.{ }^{-1}\right)$, que não diferiu do tratamento com aplicação apenas foliar (27,7 folhas planta $\left.{ }^{-1}\right)$ conforme mostrado na Tabela 4.

Aos 60 DAS a salinidade afetou negativamente o número de folhas independente do uso de bioestimulante, obtendo-se redução média de 47,4\% na maior salinidade. Em condições de estresse salino é comum ocorrerem alterações morfológicas e anatômicas nas plantas refletindo redução de transpiração como alternativa para manter a absorção de água; uma dessas adaptações é a redução do número de folhas.

Com relação ao efeito do bioestimulante, verificaram-se os menores valores nas plantas que receberam aplicação do produto via tratamentos de sementes + aplicação foliar 20 DAS, e sementes mais aplicação foliar 40 DAS, que não diferiram entre si e apresentaram média de 33 folhas planta ${ }^{-1}$; os demais tratamentos não diferiram entre si, apresentando maiores valores com média de 40,1 folhas planta-1 (Tabela 4).

Tabela 4. Valores médios para número de folhas de feijão caupi aos 20, 40 e 60 dias após a semeadura (DAS), em função da salinidade da água e aplicação de bioestimulante

\begin{tabular}{|c|c|c|c|c|c|c|c|c|c|}
\hline \multirow{3}{*}{ Bioestimulante } & \multicolumn{9}{|c|}{ Salinidades ( $\mathrm{dS} \mathrm{m}^{-1}$ ) } \\
\hline & 0,5 & 5,0 & \multirow{2}{*}{ Média } & 0,5 & 5,0 & \multirow{2}{*}{ Média } & 0,5 & 5,0 & \multirow{2}{*}{ Média } \\
\hline & \multicolumn{2}{|c|}{20 DAS } & & \multicolumn{2}{|c|}{40 DAS } & & \multicolumn{2}{|c|}{60 DAS } & \\
\hline Ausência & 10,0 & 10,0 & $10,0 \mathrm{a}$ & $44,3 \mathrm{Aab}$ & $33,1 \mathrm{Ba}$ & 38,7 & 56,8 & 31,8 & $44,3 \mathrm{a}$ \\
\hline Sementes & 9,7 & 7,8 & $8,7 \mathrm{a}$ & $47,1 \mathrm{Aab}$ & $25,1 \mathrm{Bb}$ & 36,1 & 55,3 & 25,1 & $40,2 a b$ \\
\hline Foliar (20 DAS) & - & - & - & $50,5 \mathrm{Aa}$ & 27,6 Bab & 39,0 & 50,8 & 27,6 & $39,2 a b$ \\
\hline Foliar (40 DAS) & - & - & - & $41,8 \mathrm{Ab}$ & $24,5 \mathrm{Bb}$ & 33,1 & 48,3 & 31,0 & $39,6 a b$ \\
\hline Sementes + foliar (20 DAS) & - & - & - & - & - & - & 43,1 & 24,5 & $33,8 \mathrm{~b}$ \\
\hline Sementes + foliar (40 DAS) & - & - & - & - & - & - & 43,8 & 20,6 & $32,2 \mathrm{~b}$ \\
\hline Foliares (20 e 40 DAS) & - & - & - & - & - & - & 51,8 & 22,8 & $37,3 a b$ \\
\hline Médias & $9,8 A^{*}$ & $8,9 \mathrm{~A}$ & & 45,9 & 27,6 & & $50,0 \mathrm{~A}$ & $26,2 \mathrm{~B}$ & \\
\hline
\end{tabular}

\footnotetext{
* Médias seguidas pelas mesmas letras maiúsculas nas linhas e minúsculas nas colunas não diferem entre si pelo teste de Tukey a 0,05 de probabilidade
} 
Para a área foliar não houve efeito significativo da salinidade aos 20 DAS, sendo obtida área foliar média de 132,3 $\mathrm{cm}^{2}$ planta ${ }^{-1}$. Com relação ao efeito do bioestimulante também aos 20 DAS, foi verificada resposta negativa ao tratamento de sementes com este produto de forma que os maiores valores ocorreram na ausência do bioestimulante (Tabela 5).

$\mathrm{Na}$ avaliação realizada aos $40 \mathrm{DAS}$ verificou-se efeito significativo e negativo da salinidade sobre a área foliar em todos os tratamentos com bioestimulante, além de redução média de $47,1 \%$ nas plantas irrigadas com água com salinidade $5,0 \mathrm{dS} \mathrm{m}^{-1}$. Quanto ao bioestimulante, verificaram-se os maiores valores na ausência do biestimulante e com aplicação foliar aos 20 DAS obtendo-se, entre esses, valor médio da área foliar de $1443,9 \mathrm{~cm}^{2}$ planta $^{-1}$ enquanto nos tratamentos contendo aplicação via semente (sementes e sementes + foliar aos 20 DAS) foram obtidos os menores valores, com média de $1221,4 \mathrm{~cm}^{2}$ planta $^{-1}$, correspondente à diferença percentual de 18,2\% (Tabela 5).

$\mathrm{Na}$ avaliação realizada aos 60 DAS houve interação significativa entre os fatores, de maneira que foi realizado o desdobramento para avaliar o efeito da salinidade em cada forma de aplicação do bioestimulante e o efeito do bioestimulante em cada nível de salinidade. Verificou-se redução significativa da área foliar do feijoeiro em resposta ao estresse salino, independente da forma de aplicação do bioestimulante ou da sua ausência, com redução média de 51,9\% (Tabela 5).

Sabe-se que em condições adversas as plantas desenvolvem formas de adaptação, resultando em alterações bioquímicas e/ ou morfológicas. Entre estas se destaca a redução da área foliar relacionada, possivelmente, a um dos mecanismos de adaptação ao estresse salino diminuindo a superfície transpirante (Tester \& Davenport, 2003) fato este também observado por Silva et al. (2011) e Dutra et al. (2011).
Para o efeito do bioestimulante verificou-se que a área foliar apresentou resposta variada de acordo com o tipo de aplicação, efeito este foi influenciado pela salinidade da água de irrigação. Fazendo o desdobramento para avaliar o efeito do bioestimulante na menor salinidade $\left(0,5 \mathrm{dS} \mathrm{m}^{-1}\right)$ verificaram-se os maiores valores com aplicação do bioestimulante via foliar aos 40 DAS $\left(2510,7 \mathrm{~cm}^{2}\right.$ planta $\left.{ }^{-1}\right)$, seguido do tratamento ausência e aplicação foliar aos 20 DAS, com 2089,7 e 2001,7 $\mathrm{cm}^{2}$ planta $^{-1}$, que não diferiram entre si, estatisticamente; já os menores valores ocorreram nos três tratamentos que continham aplicação via tratamento de sementes, além do tratamento com duas aplicações foliares (Foliar $20+40$ DAS), com área foliar média de $1648,7 \mathrm{~cm}^{2}$ planta $^{-1}$ (Tabela 5). Klahold et al. (2006) verificaram, estudando a cultura da soja utilizando bioestimulante, maiores valores de área foliar na ausência do produto e que a combinação tratamento de sementes mais aplicação foliar resultou em redução na área foliar.

Considerando as plantas irrigadas com água de maior salinidade $\left(5,0 \mathrm{dS} \mathrm{m}^{-1}\right)$ verificou-se que não houve efeito do bioestimulante demonstrando, assim, que o estresse salino inibiu a ação do Stimulate ${ }^{\circledR}$ (Tabela 5).

Para o acúmulo de biomassa constatou-se efeito significativo da interação entre os fatores salinidade da água de irrigação e bioestimulante sobre massa seca de folhas (MSF), de caule (MSC) e da parte aérea (MSPA); no entanto, apenas a salinidade afetou o efeito do bioestimulante.

Todas essas variáveis (MSF, MSC e MSPA) foram afetadas pela salinidade com as maiores reduções ocorrendo nos tratamentos com aplicação de bioestimulante via sementes + Foliar aos 20 DAS, com perdas de 76,0\% para MSF, 73,6\% para MSC e 74,5\% para MSPA (Tabela 6).

Tabela 5. Valores médios para área foliar $\left(\mathrm{cm}^{2}\right.$ planta $\left.^{-1}\right)$ de feijão caupi aos 20, 40 e 60 dias após a semeadura (DAS), em função da salinidade da água e aplicação de bioestimulante

\begin{tabular}{|c|c|c|c|c|c|c|c|c|c|}
\hline \multirow{3}{*}{ Bioestimulante } & \multicolumn{9}{|c|}{ Salinidades (dS m-1) } \\
\hline & 0,5 & 5,0 & \multirow{2}{*}{ Média } & 0,5 & 5,0 & \multirow{2}{*}{ Média } & 0,5 & 5,0 & \multirow{2}{*}{ Média } \\
\hline & \multicolumn{2}{|c|}{20 DAS } & & \multicolumn{2}{|c|}{40 DAS } & & \multicolumn{2}{|c|}{60 DAS } & \\
\hline Ausência & 150,6 & 167,0 & $158,8 \mathrm{a}$ & 1792,0 & 819,7 & $1305,8 \mathrm{ab}$ & $2089,7 \mathrm{Aab}$ & $988,5 \mathrm{Ba}$ & 153,0 \\
\hline Sementes & 95,8 & 115,8 & $105,8 \mathrm{~b}$ & 1609,6 & 956,0 & $1282,8 \mathrm{~b}$ & $1856,8 \mathrm{Abc}$ & $956,0 \mathrm{Ba}$ & 1406,4 \\
\hline Foliar (20 DAS) & - & - & - & 1501,7 & 818,3 & $1160,0 \mathrm{~b}$ & $2001,7 \mathrm{Abc}$ & $1095,8 \mathrm{Ba}$ & 1548,8 \\
\hline Foliar (40 DAS) & - & - & - & 2068,4 & 1095,8 & $1582,1 \mathrm{a}$ & $2510,7 \mathrm{Aa}$ & $1009,2 \mathrm{Ba}$ & 1759,9 \\
\hline Sementes + foliar (20 DAS) & - & - & - & - & - & - & $1501,7 \mathrm{Ac}$ & $822,8 \mathrm{Ba}$ & 1162,2 \\
\hline Sementes + foliar (40 DAS) & - & - & - & - & - & - & $1569,7 \mathrm{Abc}$ & $599,4 \mathrm{Ba}$ & 1084,5 \\
\hline Foliares (20 e 40 DAS) & - & - & - & - & - & - & $1666,7 \mathrm{Abc}$ & $869,2 \mathrm{Ba}$ & 1268,0 \\
\hline Médias & $123,2 \mathrm{~A}$ & $141,5 \mathrm{~A}$ & & $1742,9 \mathrm{~A}$ & $922,5 \mathrm{~B}$ & & 1885,3 & 905,8 & \\
\hline
\end{tabular}

* Médias seguidas pelas mesmas letras maiúsculas nas linhas, e minúsculas nas colunas não diferem entre si pelo teste de Tukey a 0,05 de probabilidade

Tabela 6. Valores médios para massa seca $\left(\mathrm{g}_{\text { planta-1 }}{ }^{-1}\right.$ ) de folhas (MSF), de caule (MSC) e da parte aérea (MSPA) de feijão caupi em função da salinidade da água e aplicação de bioestimulante

\begin{tabular}{|c|c|c|c|c|c|c|c|c|c|}
\hline \multirow{3}{*}{ Bioestimulante } & \multicolumn{9}{|c|}{ Salinidades $\left(\mathrm{dS} \mathrm{m}^{-1}\right)$} \\
\hline & 0,5 & 5,0 & \multirow{2}{*}{ Média } & 0,5 & 5,0 & \multirow{2}{*}{ Média } & 0,5 & 5,0 & \multirow{2}{*}{ Média } \\
\hline & \multicolumn{2}{|c|}{ MSF } & & \multicolumn{2}{|c|}{ MSC } & & \multicolumn{2}{|c|}{ MSPA } & \\
\hline Ausência & $25,3 \mathrm{Ac}$ & $15,80 \mathrm{Bab}$ & 20,6 & $34,8 \mathrm{Aa}$ & $15,3 \mathrm{Ba}$ & 25,10 & $50,1 \mathrm{Abc}$ & $29,2 \mathrm{Bab}$ & 39,6 \\
\hline Sementes & 29,4 Aab & $11,20 \mathrm{Bab}$ & 20,3 & 33,9 Aab & $11,7 \mathrm{Ba}$ & 22,88 & 63,3 Aab & 22,9 Bab & 43,2 \\
\hline Foliar (20 DAS) & 27,4 Aab & $11,60 \mathrm{Bab}$ & 19,5 & 31,6 Aab & $15,9 \mathrm{Ba}$ & 23,70 & 59,0 Aabc & 27,6 Bab & 43,3 \\
\hline Foliar (40 DAS) & 28,7 Aab & $17,00 \mathrm{Ba}$ & 22,8 & $32,2 \mathrm{Aab}$ & $14,4 \mathrm{Ba}$ & 23,30 & 60,9 Aabc & $31,4 \mathrm{Ba}$ & 46,2 \\
\hline Sementes + foliar (20 DAS) & $33,1 \mathrm{Aa}$ & $7,94 \mathrm{Bb}$ & 20,5 & $36,3 \mathrm{Aa}$ & $9,6 \mathrm{Ba}$ & 22,90 & $69,4 \mathrm{Aa}$ & $17,5 \mathrm{Bb}$ & 43,5 \\
\hline Sementes + foliar (40 DAS) & $23,9 \mathrm{Ab}$ & $14,20 \mathrm{Bab}$ & 19,0 & 33,8 Aab & $14,9 \mathrm{Ba}$ & 24,40 & 57,7 Aabc & 29,1 Bab & 43,5 \\
\hline Foliares (20 e 40 DAS) & $21,3 \mathrm{Abc}$ & $15,20 \mathrm{Bab}$ & 18,3 & $27,3 \mathrm{Ab}$ & $11,7 \mathrm{Ba}$ & 19,50 & $48,6 \mathrm{Ac}$ & $26,9 \mathrm{Bab}$ & 37,7 \\
\hline Médias & 27,0 & 13,00 & & 28,8 & 11,7 & & 51,2 & 23,1 & \\
\hline
\end{tabular}

* Médias seguidas pelas mesmas letras maiúsculas nas linhas e minúsculas nas colunas não diferem entre si pelo teste de Tukey a 0,05 de probabilidade; DAS - dias após a semeadura 
Na maior salinidade $\left(5,0 \mathrm{dS} \mathrm{m}^{-1}\right)$ os menores valores foram encontrados nas plantas que receberam tratamento via sementes + foliar aos 20 DAS (Tabela 6); esses resultados demonstram que o uso do bio estimulante não reduziu o efeito deletério da salinidade sobre o acúmulo de biomassa pelo feijoeiro. O efeito da salinidade sobre a massa seca de folhas do feijão caupi tem sido relatado por vários autores (Sousa et al., 2007; Neves et al., 2009; Silva et al., 2011 e Souza et al., 2011). A menor produção de fotoassimilados pelas plantas cultivadas em condições salinas reflete o efeito da redução do potencial osmótico da solução do solo inibindo a absorção de água pela planta (Figueirêdo et al., 2009). Resultados semelhantes foram obtidos para outras culturas, como melão (Gurgel et al., 2010), pepino (Medeiros et al., 2009) e abóbora (Carmo et al., 2011).

Com relação ao efeito da aplicação do Stimulate ${ }^{\circledR}$ em cada nível de salinidade sobre a MSF, ficou patente que nas plantas irrigadas com água de salinidade $0,5 \mathrm{dS} \mathrm{m}^{-1}$, os maiores valores de massa seca de folhas ocorreram com aplicação do Stimulate ${ }^{\circledR}$ e o menor na ausência do produto e com aplicação foliar aos 20 e 40 DAS (Tabela 6). Para MSC houve resposta ao bioestimulante na menor salinidade, com menores valores para aplicações foliares aos 20 e 40 DAS enquanto as demais formas de aplicação não diferiram entre si estatisticamente. Na salinidade de $5,0 \mathrm{dS} \mathrm{m}^{-1}$ não houve resposta ao bioestimulante visto que o estresse salino inibiu o efeito do Stimulate ${ }^{\circledR}$ (Tabela 6).

Quanto a MSPA, os menores valores foram verificados nas plantas irrigadas com água menos salina quando ocorreram nas aplicações foliares de Stimulate ${ }^{\circledR}$ aos 20 e 40 DAS enquanto na maior salinidade os menores valores de MSPA foram obtidos nas plantas que receberam tratamentos via sementes + foliar aos 20 DAS. Apesar de não haver diferença significativa entre os demais tratamentos, pode-se verificar, de forma geral, que nos tratamentos nos quais as plantas oriundas de sementes tratadas com bioestimulante, apresentaram maior sensibilidade à salinidade (Tabela 6).

Em geral, verificou-se que a resposta das plantas ao Stimulate ${ }^{\circledR}$ pode ser variável, além das condições ambientais, da fase fenológica da cultura na qual é utilizado o regulador vegetal de crescimento corroborando com os resultados encontrados por Alleoni et al. (2000) e Abrantes et al. (2011) que verificaram diferença significativa no desenvolvimento das plantas, de acordo com a época de aplicação do bioestimulante.

Os resultados obtidos neste trabalho e em confronto com outros encontrados na literatura demonstram a viabilidade do uso de bioestimulante na produção agrícola; no entanto, o sucesso do uso deste produto está diretamente dependente das condições ambientes de produção, bem como do material genético utilizado; desta forma, é de fundamental importância o desenvolvimento de novas pesquisas com outras espécies e variedades, condições ambientais e de manejo, bem como a dosagem, uma vez que a eficiência do bioestimulante pode ser influenciada por tais fatores.

\section{Conclusões}

1. O uso de bioestimulante favoreceu o desenvolvimento do feijoeiro apenas nas plantas irrigadas com água não salina.
2. O estresse salino provocou redução nos parâmetros de desenvolvimento do feijão caupi principalmente nas plantas que receberam aplicações de bioestimulante.

3. A salinidade da água de irrigação inibiu o efeito benéfico do bioestimulante no desenvolvimento do feijoeiro.

4. O uso do bioestimulante não é indicado em condições nas quais seja inevitável o uso de água salina na irrigação.

\section{Agradecimentos}

Os autores agradecem à UFERSA, pela disponibilidade da estrutura, e ao Instituto Nacional de Ciência e Tecnologia em Salinidade (INCTSal) pelo apoio financeiro necessário ao desenvolvimento desta pesquisa.

\section{Literatura Citada}

Abrantes, F. L.; Sá, M. E.; Souza, L. C. D.; Silva, M. P.; Simidu, H. M.; Andreotti, M.; Buzetti, S.; Valério Filho, W. V.; Arruda, N. Uso de regulador de crescimento em cultivares de feijão de inverno. Pesquisa Agropecuária Tropical, v.41, p.148-154, 2011.

Alleoni, F.; Bosqueiro, M.; Rossi, M. Efeito dos reguladores vegetais de Stimulate no desenvolvimento e produtividade do feijoeiro (Phaseolus vulgaris). Ciências Exatas e da Terra, Ciências Agrárias e Engenharias, v.6, p.23-35, 2000.

Ávila, M. R.; Barizão, D. A. O.; Gomes, E. P.; Fedri, G.; Albrecht, L. P. Cultivo de feijoeiro no outono/inverno associado à aplicação de bioestimulante e adubo foliar na presença e ausência de irrigação. Scientia Agraria, v.11, p.221-230, 2010.

Ayers, R. S.; Westcot, D. W. A. Qualidade da água na agricultura. Campina Grande: UFPB, 1999. 153p. Estudos FAO: Irrigação e Drenagem, 29

Baldo, R.; Scalon, S. P. Q.; Rosa, Y. B. C. J.; Mussury, R. M.; Betoni, R.; Barreto, W. S. Comportamento do algodoeiro cultivar delta opal sob estresse hídrico com e sem aplicação de bioestimulante. Ciência e Agrotecnologia, v.33, p.18041812, 2009.

Bertolin, D. C.; Sá, M. E.; Arf, O.; Furlani Junior, E.; Colombo, A. S.; Carvalho, F. L. B. M. Aumento da produtividade de soja com a aplicação de bioestimulantes. Bragantia, v.69, p.339-347, 2010.

Bezerra, A. K. P.; Lacerda, C. F.; Hernandez, F. F. F.; Silva, F. B.; Gheyi, H. R. Rotação cultural feijão caupi/milho utilizando-se águas de salinidades diferentes. Ciência Rural, v.40, p.1075-1082, 2010.

Carmo, G. A.; Oliveira, F. R. A.; Medeiros, J. F.; Oliveira, F. A.; Campos, M. S.; Freitas, D. C. Teores foliares, acúmulo e partição de macronutrientes na cultura da abóbora irrigada com água salina. Revista Brasileira de Engenharia Agrícola e Ambiental, v.15, p.512-518, 2011.

Castro, P. R. C.; Vieira, E. L. Aplicações de reguladores vegetais na agricultura tropical. Guaíba: Livraria e Editora Agropecuária, 2001. 132p.

Domingues, M. C. S.; Rodrigues, J. D.; Moreira, R. C. Efeito de reguladores vegetais (auxina, giberelina e citocinina) na produtividade da cultura da soja (Glycine $\max (\mathrm{L}$.) Merrill cv. IAC - 48). In: Congresso Brasileiro de Soja, 3, 2004, Foz do Iguaçu. Anais... Foz do Iguaçu: Embrapa Soja, 2004. CD-Rom 
Dutra, A. T. B.; Silva, E. N.; Rodrigues, C. R. F.; Vieira, S. A.; Aragão, R. M.; Silveira, J. A. G. A.Temperaturas elevadas afetam a distribuição de íons em plantas de feijão caupi pré-tratadas com $\mathrm{NaCl}$. Revista Brasileira de Engenharia Agrícola e Ambiental, v.15, p.403-409, 2011.

EMBRAPA - Empresa Brasileira de Pesquisa Agropecuária Centro Nacional de Pesquisa de Solos. Manual de métodos de análise de solos. 2.ed. Rio de Janeiro: Embrapa CNPS, 1997. 212p.

EMBRAPA - Empresa Brasileira de Pesquisa Agropecuária. Sistema brasileiro de classificação de solos. 2.ed. Rio de Janeiro: EMBRAPA, 2006. 306p.

Figueirêdo, V. B.; Medeiros, J. F. de; Zocoler, J. L.; Espínola Sobrinho, J. Evapotranspiração da cultura da melancia irrigada com água de diferentes salinidades. Engenharia Agrícola, v.29, p.231-240, 2009.

Garcia, R. A.; Gazola, E.; Merlin, A.; Villas Bôas, R. L.; Crusciol, C. A. C. Crescimento aéreo e radicular de arroz de terras altas em função da adubação fosfatada e bioestimulante. Bioscience Journal, v.25, p.65-72, 2009.

Gurgel, M. T.; Uyeda, C. A.; Gheyi, H. R.; Oliveira, F. H. T.; Fernandes, P. D.; Silva, F. V. Crescimento de meloeiro sob estresse salino e doses de potássio. Revista Brasileira de Engenharia Agrícola e Ambiental, v.14, p.3-10, 2010.

Klahold, C. A.; Guimarães, V. F.; Echer, M. M.; Klahold, A.; Contiero, R. L.; Becker, A. Resposta da soja (Glycine max (L.) Merrill) à ação de bioestimulante. Acta Scientiarum. Agronomy, v.28, p.179-185, 2006.

Lacerda, C. F.; Sousa, G. G.; Silva, F. L. B.; Guimarães, F. V. A.; Silva, G. L.; Cavancante, L. F. Soil salinization and maize and cowpea yield in the crop rotation system using saline waters. Engenharia Agrícola, v.31, p.663-675, 2011.

Lima, C. J. G. L.; Oliveira, F. A.; Medeiros, J. F.; Oliveira, M. K. T.; Oliveira Filho, A. F. Modelos matemáticos para estimativa de área foliar de feijão caupi. Revista Caatinga, v.21, p.120-127, 2008.

Lima, M. A.; Castro, V. F.; Vidal, J. B.; Enéas-Filho, J. Aplicação de silício em milho e feijão-de-corda sob estresse salino. Revista Ciência Agronômica, v.42, p.398-403, 2011.
Medeiros, J. F. Qualidade da água de irrigação utilizada nas propriedades assistidas pelo "GAT" nos Estados do RN, PB, $\mathrm{CE}$ e avaliação da salinidade dos solos. Campina Grande: UFPB, 1992. 173p. Dissertação Mestrado

Medeiros, P. R. F.; Duarte, S. N.; Dias, C. T. S. Tolerância da cultura do pepino a salinidade em ambiente protegido. Revista Brasileira de Engenharia Agrícola e Ambiental, v.13, p.406-410, 2009.

Mousinho, F. E. P.; Andrade Júnior, A. S.; Frizzone, J. A. Viabilidade econômica do cultivo irrigado do feijão-caupi no Estado do Piauí. Acta Scientiarun Agronomy, v.30, p.139-145, 2008.

Munns, R. Genes and salt tolerance: bringing them together. New Phytologist, v.167, p.645-663, 2005.

Neves, A. L. R.; Lacerda, C. F.; Guimarães, F. V. A.; Hernandez, F. F. F.; Silva, F. B.; Prisco, J. T.; Gheyi, H. R. Acumulação de biomassa e extração de nutrientes por plantas de feijãode-corda irrigadas com água salina em diferentes estádios de desenvolvimento. Ciência Rural, v.39, p.758-765, 2009.

Silva, F. L. B.; Lacerda, C. F.; Sousa, G. G.; Neves, A. L. R.; Silva, G. L.; Sousa, C. H. C. Interação entre salinidade e biofertilizante bovino na cultura do feijão-de-corda. Revista Brasileira de Engenharia Agrícola e Ambiental, v.15, p.383-389, 2011.

Sousa, R. A.; Lacerda, C. F.; Amaro Filho, J.; Hernandez, F. F. F. Crescimento e nutrição mineral do feijão-de-corda em função da salinidade e da composição iônica da água de irrigação. Revista Brasileira de Ciências Agrárias, v.2, p.75-82, 2007.

Souza, R. P.; Machado, E. C.; Silveira, J. A. G.; Ribeiro, R. V. Fotossíntese e acúmulo de solutos em feijoeiro caupi submetido à salinidade. Pesquisa Agropecuária Brasileira, v.46, p.586-592, 2011.

Tester, M.; Davenport, R. $\mathrm{Na}^{+}$tolerance and $\mathrm{Na}^{+}$transport in higher plants. Annals of Botany, v.91, p.503-527, 2003.

Vieira, E. L.; Castro, P. R. C. Ação de bioestimulante na cultura da soja (Glycine max L. Merrill). Cosmópolis: Stoller do Brasil, 2004. 47p. 